\title{
Optimising Quantity of Manufacturing and Re- manufacturing in an Electric Vehicle Battery Closed-loop Supply Chain
}

\author{
Xiaoyu Gu, Petros Ieromonachou, Li Zhou \\ Department of Systems Management \& Strategy, University of Greenwich, London, UK \\ Ming-Lang Tseng \\ Lung-Hwa University of Science and Technology, Taiwan
}

\begin{abstract}
Purpose - Batteries installed on electric vehicles (EVs) should normally be removed when their capacity falls to $70-80 \%$, but they are still usable for other purposes, such as energy storage. This paper studies an EV battery closed-loop supply chain (CLSC) consisting of a battery manufacturer and a remanufacturer. The manufacturer produces new batteries by using natural resources, while the remanufacturer collects returned batteries and makes decisions based on the return quality, that is, to reuse or recycle. The purpose of this research is to maximise the individual profits through optimising the amount of manufacturing and remanufacturing respectively, and optimising the purchase price of returned batteries.
\end{abstract}

Design/methodology/approach - Based on the Nash equilibrium, this paper develops a three-period model in the CLSC. In period 1, batteries are made from raw materials; in period 2, returned batteries from period 1 are sorted into low quality and high quality. Some high-quality returns can be reused for other purposes while those non-reusable returns are recycled into materials. In period 3, all the returns are recycled into materials. The analytical results are derived.

Findings - The result of the analyses suggest that (a) among the variables that affect the (re-)manufacturing decision, the purchase price for returned batteries plays a critical role. In particular, the price of low-quality returns has more influence than the price of high quality returns. (b) Interestingly, the higher purchase price for re-usable returns does not necessarily lead to a higher return rate of reusable returns. (c) The manufacturer's profit is normally higher than the remanufacturer's. This suggests the need to design incentives to promote the remanufacturing sector. (d) Although it is appreciated that maximising the utilisation of batteries over the life-cycle would benefit the environment, the economic benefit needs further investigation.

Originality/value - Although the CLSC has been widely studied, studies on the EV battery CLSC are scarce. The EV battery CLSC is particularly challenging in terms of the reusability of returns because used EV batteries cannot be reused for the original purpose, which complicates CLSC operations. This paper explores the interrelationship between manufacturer and remanufacturer, explaining the reasons why recycling is still underdeveloped, and suggests the possibility of enhancing remanufacturing profitability.

Key words - Closed-loop supply chain, Electric vehicle battery, Recycle, Reuse, Purchasing price, Profit 
Paper type - Research paper

\section{Introduction}

With the aim of achieving sustainable development, electric vehicles (EVs) are considered one of the future directions for the automotive industry. One of the earliest studies regarding EV's history, progress and advantages can be found in Turner and Heusinger (1984). In the 21st century, the EV industry is developing and the uptake of EVs is increasing rapidly. According to the International Energy Agengy (2016), from 2005 to 2010 the number of EV sales, including pure battery EVs and plug-in hybrid EVs (PHEVs), increased from 1670 to 12,480 worldwide. Since then, the number of new-energy vehicles has been increased even more sharply. By 2015, the stock of EVs was 1,256,900, which is almost 752 times higher than 10 years ago.

One of the most important components of an EV is the battery. The high uptake of EVs leads to a high demand for EV batteries. The battery's operating life affects the EV's mileage directly. For example, Tesla model S P90D's battery duration is $430 \mathrm{~km}$ with an embedded 95kWh battery (Tesla, 2016). The working mileage of an EV battery may affect the desirability to customers of buying an EV. Unlike gasoline vehicles, EVs cannot use their batteries until they reach the end of their life-cycle. Instead, the batteries have to be removed when their capacity fall to around $70-80 \%$ due to performance and safety concerns (McIntire-Strasburg, 2015). In early 2010, the US National Renewable Energy Laboratory undertook a project on EV battery reuse (Neubauer and Pesaran, 2010). The report shows that a recycled battery can be reused in the following ways: (a) grid-based stationary, for example energy time shifting, renewables capacity firming; (b) off-grid stationary, for example backup power and remote installations; and (c) mobile, for example commercial idle management or public transportation. Those applications for EV second use could significantly increase the total lifetime value of money, and thus reduce the cost to the electric automotive user.

Most of the research studying the reuse of EV batteries has focused on the technical aspects (e.g. Lih et al., 2012; Neubauer and Pesaran, 2011; Patten et al., 2011; Yu et al., 2013). How reuse of EV batteries affects the operational performance and profit of the closed-loop supply chain (CLSC) remains untouched. From an operations management point of view, research lags behind the industry. In response to automotive batteries being banned from landfill or incineration, EV battery collection and recycling networks have been built. Nevertheless, most of the returned batteries are recycled into materials rather than being reused. To deal with this issue, some industrial initiatives exist, for instance in North America, Tesla, working with Kinsbursky Brothers, recycled about $60 \%$ of its battery packs; in Europe, Tesla started working with Umicore on recycling (Kelty, 2011); and Nissan and Volkswagen require their EV customers to return used batteries to licensed points or local authority battery collection schemes (Nissan, 2015; Volkswagen, 2016). Now more and more EV manufacturers are involved in reusing EV batteries. For example, BMW and Nissan are expected to reuse returned batteries as home energy storage (Ayre, 2016; Dalton, 2016). Chevrolet has set up an energy storage station by using used EV batteries at the General Motors facility in 
Michigan (Voelcker, 2016).

Inspired by these applications, we built a three-period model to describe the EV CLSC process. There are two participants in the model: the manufacturer, who produces new EV batteries (over the three periods); and the remanufacturer, who collects used batteries and sorts them into reusable and recyclable based on the quality of the returns in period 2. The reused batteries will be recycled in period 3. In period 1, batteries are only made from raw materials. There are no returned or recycled batteries in this period. In period 2, returned batteries are sorted into low quality and high quality. The highquality returns are further sorted into reusable and recyclable. The recyclable returns will be recycled into materials. In period 3, those reused batteries reach the end of their life and will be collected and recycled into materials.

The paper is organised as follows. The next section reviews some relevant literature and clarifies our contribution to the literature. Section 3 describes the model and derives the optimal quantity, the optimal purchase price and the maximised profit for manufacturer and remanufacturer, respectively. Section 4 conducts a numerical study. Finally, Section 5 concludes our findings and discusses the limitations as well as future research.

\section{Closely related literature}

The model developed in this paper is related to EV battery reuse and recycling in a multi-period CLSC. In this section, the relevant literature on battery reuse and multiperiod SC is reviewed. The purpose is to justify the differences between our model and existing models, and hence our contribution to the literature.

Most research discusses how EV batteries can be reused from a technical point of view. There are very few studies focusing on economic benefits. Patten et al. (2011) discuss how EV batteries can be used in a wind storage system to improve utilisation and make more efficient use of EV batteries prior to recycling. Assuncao et al. (2016) built a model of how repurposed EV batteries can be used to support solar energy. The model is analysed from both technical and economic aspects. In their model, they allow users to generate energy and inject it into the grid for economic benefits. As shown in that paper, the used batteries could be reused for more than 10 years and will bring a good payback to customers. Ahmadi et al. (2014) and Aziz et al. (2015) studied the performance of reused EV batteries in rebalancing the electricity grid. They state that if repurposed batteries are used to store off-peak electricity to serve peak demand, carbon dioxide $\left(\mathrm{CO}_{2}\right)$ emissions will be reduced by around $56 \%$. However, some people have different views. Although used EV batteries could be a potential enhancement of cost-effective energy storage, Neubauer and Pesaran (2011) argue that even though the second use of the batteries is not expected to significantly affect PHEV/EV price, longterm battery degradation and second-use applications need to be investigated in more detail.

The CLSC is a well-studied yet challenging area in particular when it becomes a multi-period model. There are several papers that study a two-period model (Atasu et al., 2008; Ferguson and Toktay, 2006; Mitra and Webster, 2008; Webster and Mitra, 2007; Majumder and Groenevelt, 2001), most of which focus on the relationship and 
decision making between manufacturer and remanufacturer. For instance, Majumder and Groenevelt (2001) study a two-period competition model between an original equipment manufacturer (OEM) and a local remanufacturer by fixing the total cost for dealing with the returned items. The model developed by Mitra and Webster (2008) analyses the regulation of remanufacturing activities. Moreover, from the multi-period aspect, Ferrer and Swaminathan (2010) analyse the (re)manufacturer monopoly environment from a two-period to a multi-period planning horizon, and develop a strategy for optimising price for the firm in the model.

The literature review suggests that the existing multi-period CLSC models do not reflect the practices of used EV battery reuse and recycling and the characteristics of such CLSC; that is, unlike normal goods, EV batteries cannot be reused for their original purpose, which complicates normal CLSC operations. Therefore, the contribution of this study is to fill the CLSC research gap in EV battery recycling and reuse. This paper explores the interrelationship between EV battery manufacturer and remanufacturer, explains the reasons why recycling is still underdeveloped.

Our study is closely related to two models. The first is a general two-period model designed by Bulmus et al. (2014), which involves an OEM and an independently operating remanufacturer (IO). In period 1, only the OEM is included, while in period 2 both OEM and IO are included in competition. The authors analyse the manufacturing/remanufacturing optimal quantity and profit under Nash equilibrium conditions. Relationships between these and several different parameters - that is, market size, (re)manufacturing cost in each period, return rate and so on - are discussed in their model. In this paper, we expand the model from a two-period to a three-period model, where returned batteries are reused before being recycled into materials in period three. This is moreover similar to Cai et al. (2014), whose model studies the optimal acquisition and production policy in a hybrid manufacturing and remanufacturing system including high-quality core remanufacturer and low-quality core remanufacturer. In our model, we further classify the returned batteries into high quality, low quality and reusable returns.

\section{Model description and formulation}

We consider a three-period model to describe an EV battery manufacturing/ remanufacturing system as shown in Figure 1. 


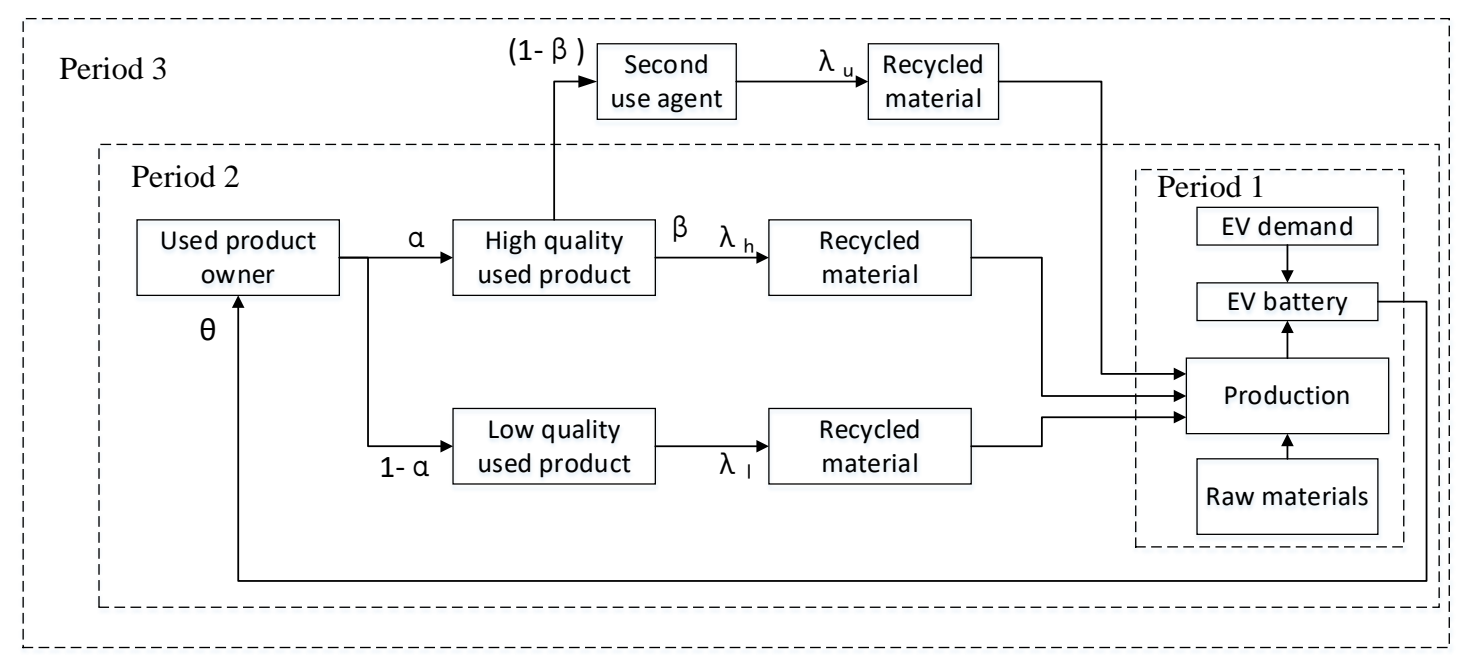

Figure 1: A three-period model in a manufacturing/remanufacturing system

- In period 1, all EV batteries are made from raw materials. The battery manufacturing quantity is based on the EV demand.

- In period 2, the batteries are made from raw materials and recycled materials from returned batteries, both high and low quality. A proportion, $\theta$, of used EV batteries is returned. According to Erp-batteries (2012) and Gaines and Singh (1995), recycled batteries have different conditions so their values are different. We classify returns into two levels: $\alpha$ refers to the proportion of high-quality returns and $(1-\alpha)$ to low-quality returns. Then, high-quality returns will be sorted further. $\beta$ refers to the proportion that is recycled into materials, and $(1-\beta)$ the proportion that is reused in other places for a certain period. This means that these reused batteries will not be recycled in period 2. Furthermore, because there will be a loss in the process, we set $\lambda_{l}$ and $\lambda_{h}$ as the remanufacturing rates for low- and high- quality returns, respectively. We assume that the remanufacturing cost for low-quality returns is higher than that for high-quality returns, that is, $c_{2 h}<C_{2 l}$.

- In period 3, the reused batteries reach the end of their life and they will be recycled as well. Hence, in this period batteries are made from raw materials and recycled materials from high- and low- quality returns as well as reused batteries. The recycling rate for reused batteries is $\lambda_{u}$.

All the notations used are listed in Table 1.

Table 1: Notations

\begin{tabular}{|l|l|l|l|}
\hline General parameters & $\begin{array}{l}\text { Potential EV market size in } \\
\text { period } i\end{array}$ & $A$ & $\begin{array}{l}\text { Coefficient between } \\
\text { battery material quan- } \\
\text { tity and EV quantity: } \\
q_{i}=A q_{E V V},(A>0)\end{array}$ \\
\hline$\delta_{m} ; i=1,2,3$ & $\begin{array}{l}\text { Coefficient between EV } \\
\text { sale price and material } \\
\text { price: } \\
p_{i}=\delta_{m} p_{E V i},\left(0<\delta_{m}<1\right)\end{array}$ & $k_{E V i} ; i=1,2,3$ & $\begin{array}{l}\text { For simplification, we } \\
\text { define } \\
k_{E V i}=\delta_{m} /\left(A M_{E V i}\right)\end{array}$ \\
\hline$\theta$ & Battery return yield & $\alpha$ & $\begin{array}{l}\text { Proportion of high } \\
\text { quality returns among } \\
\text { total returns }\end{array}$ \\
\hline
\end{tabular}




\begin{tabular}{|c|c|c|c|}
\hline $1-\beta$ & $\begin{array}{l}\text { Reusable rate among high } \\
\text { quality returns }\end{array}$ & $c_{\text {nature }}$ & $\begin{array}{l}\text { Cost of purchasing raw } \\
\text { materials }\end{array}$ \\
\hline$C_{n}$ & $\begin{array}{l}\text { Manufacturing cost of new } \\
\text { battery }\end{array}$ & $C_{h}$ & $\begin{array}{l}\text { Remanufacturing cost } \\
\text { of high-quality returns }\end{array}$ \\
\hline$C_{l}$ & $\begin{array}{l}\text { Remanufacturing cost of } \\
\text { low-quality returns }\end{array}$ & $C_{u}$ & $\begin{array}{l}\text { Remanufacturing cost } \\
\text { of reused battery }\end{array}$ \\
\hline$\lambda_{h}$ & $\begin{array}{l}\text { High-quality returns' recy- } \\
\text { cling rate into materials } \\
\left(0<\lambda_{h}<1\right)\end{array}$ & $\lambda_{1}$ & $\begin{array}{lr}\text { Low-quality } & \text { returns } \\
\text { recycling } & \text { rate } \\
\left(0<\lambda_{l}<1\right) & \end{array}$ \\
\hline$\lambda_{u}$ & $\begin{array}{l}\text { Reused EV battery recy- } \\
\text { cling rate }\left(0<\lambda_{u}<1\right)\end{array}$ & $p_{E V i} ; i=1,2,3$ & EV price in period $i$ \\
\hline$q_{E V i} ; i=1,2,3$ & $\begin{array}{l}\text { Quantity of EV demand in } \\
\text { period } i\end{array}$ & & \\
\hline \multicolumn{4}{|c|}{ Decision variables } \\
\hline$p_{i} ; i=1,2,3$ & $\begin{array}{l}\text { Battery selling price in pe- } \\
\text { riod } i\end{array}$ & $q_{i} ; i=1,2,3$ & $\begin{array}{l}\text { Total amount of bat- } \\
\text { tery needed in period } \\
i\end{array}$ \\
\hline$q_{i n} ; i=1,2,3$ & $\begin{array}{l}\text { Amount of battery made } \\
\text { from raw material in pe- } \\
\text { riod } i\end{array}$ & $q_{i l} ; i=2,3$ & $\begin{array}{l}\text { Quantity of recycled } \\
\text { materials from low } \\
\text { quality returns in pe- } \\
\text { riod } i\end{array}$ \\
\hline$q_{i h} ; i=2,3$ & $\begin{array}{l}\text { Quantity of recycled mate- } \\
\text { rials from high quality re- } \\
\text { turns in period } i\end{array}$ & $s_{i l} ; i=2,3$ & $\begin{array}{l}\text { Price of purchasing } \\
\text { low-quality returns in } \\
\text { period } i\end{array}$ \\
\hline$s_{i h} ; i=2,3$ & $\begin{array}{l}\text { Price of purchasing high- } \\
\text { quality returns in period } i\end{array}$ & $S_{3 u}$ & $\begin{array}{l}\text { Price of purchasing re- } \\
\text { used batteries in period } \\
3\end{array}$ \\
\hline$q_{3 u}$ & $\begin{array}{l}\text { Quantity of batteries re- } \\
\text { manufactured from reused } \\
\text { batteries in period } 3\end{array}$ & $\Pi_{i n} ; i=1,2,3$ & $\begin{array}{l}\text { Profit for new battery } \\
\text { manufacturing in pe- } \\
\text { riod } i\end{array}$ \\
\hline$\Pi_{i l} ; i=2,3$ & $\begin{array}{l}\text { Profit for low-quality re- } \\
\text { turns remanufacturing in } \\
\text { period } i\end{array}$ & $\Pi_{i h} ; i=2,3$ & $\begin{array}{l}\text { Profit for high quality } \\
\text { returns remanufactur- } \\
\text { ing in period } i\end{array}$ \\
\hline$\Pi_{3 u}$ & $\begin{array}{l}\text { Profit for re-used battery } \\
\text { remanufacturing in period } \\
3\end{array}$ & & \\
\hline
\end{tabular}

For simplification, we assume that each of the initial parameters is the same over the three periods.

\subsection{Nash equilibrium in period 1}

This study discusses EV battery, and its manufacturing quantity is based on EV market. Assume EV market size is $M_{E V 1}$, its sale price is $p_{E V 1}$. Customer's willingness to pay for the EV is $v$. We assume that $p_{E V 1}$ and $v$ have a uniform distribution between 0 and 1, i.e., $v \in[0,1]$ and $p_{E V 1} \in[0,1]$. By adopting the same utility-based approach as Ferguson and Toktay (2006), Bulmus et al. (2014) and Debo et al. (2005), customer utility of buying EVs is $U=v-p_{E V 1}$. The quantity of EVs sold in this period becomes

$$
q_{E V 1}=M_{E V 1}\left(1-p_{E V 1}\right)
$$


Assume that the demand for battery material is $q_{1}=A q_{E V 1},(A>0)$ and the price of an EV battery for each EV is $p_{1}=\delta_{m} p_{E V 1},\left(0<\delta_{m}<1\right)$, where $A$ and $\delta_{m}$ are coefficients. As in period 1, all EV batteries are made from raw materials, that is $q_{1}=q_{1 n}$. Hence, through substituting $q_{1}$ and $p_{1}$ into (1), we have

$$
q_{1 n}=A M_{E V 1}\left(1-p_{1} / \delta_{m}\right)
$$

Let $k_{1}=\delta_{m} /\left(A M_{E V 1}\right)$ and, through formula transformation, the battery price in period 1 is

$$
p_{1}=\delta_{m}-k_{1} q_{1 n}
$$

Battery manufacturer's profit is the sale price minus both the raw materials purchasing cost and the manufacturing cost, then multiplied by the quantity of batteries sold. Through substituting (3), the profit can be expressed as:

$$
\Pi_{1 n}=\left(p_{1}-c_{n}-c_{\text {nature }}\right) q_{1 n}=\left(\delta_{m}-k_{1} q_{1 n}-c_{n}-c_{\text {nature }}\right) q_{1 n}
$$

To make the study non-trivial and allow profitable manufacturing, we let $0<\left(c_{n}+c_{\text {nature }}\right)<p_{1}<1$ to ensure the profit for the battery manufacturer is positive; that is $\Pi_{1 n}>0$.

As $\frac{\partial^{2} \Pi_{1 n}}{\partial q_{1 n}{ }^{2}}=-2 k_{1}<0, \Pi_{1 n}$ is a convex function. Therefore, the maximised profit that the battery manufacturer will achieve at $\frac{\partial \Pi_{1 n}}{\partial q_{1 n}}=0$. So, the optimal quantity for manufacturer $q_{1 n}{ }^{*}$ in period 1 is:

$$
q_{1 n}^{*}=\frac{\delta_{m}-C_{n}-C_{\text {nature }}}{2 k_{1}}
$$

We have $q_{1 n}{ }^{*}>0$ as $0<\left(c_{n}+c_{\text {nature }}\right)<\delta_{m}$. From Equation (5), we can conclude that the optimal quantity for the new battery manufacturer has negative relationship with $c_{n}$ and $c_{\text {nature }}$. This also means that, with the increase in the raw materials price and the manufacturing cost, the optimal quantity for manufacturing a new EV battery is decreasing. Meanwhile, as can be seen in Equation (3), the lower the manufacturing quantity, the higher the sale price $p_{1}$, reflecting the theory of market leverage.

\subsection{Nash equilibrium in period 2}

Similar to period 1, the demand for EVs depends on market size and EV price in period 2:

$$
q_{E V 2}=M_{E V 2}\left(1-p_{E V 2}\right)
$$

With $q_{2}=A q_{E V 2}$ and $p_{2}=\delta_{m} p_{E V 2}$, the quantity of EV batteries required in this period is:

$$
q_{2}=A M_{E V 2}\left(1-p_{2} / \delta_{m}\right)
$$

And letting $k_{2}=\delta_{m} /\left(A M_{E V 2}\right)$, we can derive the EV battery price function by the inverse of (7): 


$$
p_{2}=\delta_{m}-k_{2} q_{2}
$$

In this period, $\theta$ of batteries will be returned. These returned batteries will be sorted into three classes: reusable, high-quality and low-quality. As shown in Figure 1, reusable returns will be reused in other places, for instance, for energy storage. Only highquality and low-quality returns will be recycled into materials. Therefore, in period 2, the materials needed for producing batteries come from three parts: raw material, material recycled from high-quality returns and material recycled from low-quality returns. The demand for raw materials is the total demand for materials minus the quantity of recycled materials:

$$
q_{2 n}=q_{2}-q_{2 l}-q_{2 h}
$$

We can derive the inverse of demand function (9) by substituting (8) as follows:

$$
p_{2}=\delta_{m}-k_{2}\left(q_{2 n}+q_{2 l}+q_{2 h}\right)
$$

The total return at period 2 is the return rate $\theta$ multiplied by the quantity of existing battery material in the previous period, $A \theta q_{E V 1}$.

Applying the utility-based concepts as described in period 1, assuming that the purchasing price for returns, both high quality and low quality, obeys a uniform distribution [0,1], we derive the return quantity for high and low quality in Equation (11):

$$
\left\{\begin{array}{l}
q_{2 h}=A \theta q_{E V 1} \alpha \beta\left(1-s_{2 h}\right) \\
q_{2 l}=A \theta q_{E V 1}(1-\alpha)\left(1-s_{2 l}\right)
\end{array}\right.
$$

Because of different values for different qualities, we have $s_{2 h}>s_{2 l}$.

The quantity of materials made from different classes of return is the return quantity multiplied by the returned batteries salvageable rate, $\lambda_{h}$ and $\lambda_{l}$. The profit for manufacturer and remanufacturer is defined as battery sales revenue minus recycling cost and returned battery purchase price. Hence, by substituting (10), profit functions for manufacturer and remanufacturer (e.g. both low-quality and high-quality) are:

$$
\left\{\begin{array}{l}
\Pi_{2 n}=\left(p_{2}-c_{n}-c_{\text {nature }}\right) q_{2 n}=\left(\delta_{m}-k_{2}\left(q_{2 n}+q_{2 l}+q_{2 h}\right)-c_{n}-c_{\text {nature }}\right) q_{2 n} \\
\Pi_{2 l}=\left(\lambda_{1} p_{2}-c_{l}-s_{2 l}\right) q_{2 l}=\left(\lambda_{1}\left(\delta_{m}-k_{2} q_{2 n}-k_{2} q_{2 l}-k_{2} q_{2 h}\right)-c_{l}-s_{2 l}\right) q_{2 l} \\
\Pi_{2 h}=\left(\lambda_{h} p_{2}-c_{h}-s_{2 h}\right) q_{2 h}=\left(\lambda_{h}\left(\delta_{m}-k_{2} q_{2 n}-k_{2} q_{2 l}-k_{2} q_{2 h}\right)-c_{h}-s_{2 h}\right) q_{2 h}
\end{array}\right.
$$

We also assume $p_{2}>c_{n}+c_{\text {nature }}, \lambda_{l} p_{2}>c_{l}+s_{2 l}$ and $\lambda_{h} p_{2}>c_{h}+s_{2 h}$ to ensure a positive profit. In addition, due to the higher loss in the recycling process for low-quality returns, we have $\lambda_{l}<\lambda_{h}$.

Through the second-order condition, we find that $\Pi_{2 n}, \Pi_{2 l}$ and $\Pi_{2 h}$ are all convex functions:

$$
\frac{\partial^{2} \Pi_{2 n}}{\partial q_{2 n}{ }^{2}}=-2 k_{2}<0 ; \frac{\partial^{2} \Pi_{2 l}}{\partial q_{2 l}{ }^{2}}=-2 \lambda_{1} k_{2}<0 ; \frac{\partial^{2} \Pi_{2 h}}{\partial q_{2 h}{ }^{2}}=-2 \lambda_{h} k_{2}<0
$$

So, they all have the maximum profit which can be achieved by using the firstorder condition, that is, $\frac{\partial \Pi_{2 n}}{\partial q_{2 n}}=\frac{\partial \Pi_{2 l}}{\partial q_{2 l}}=\frac{\partial \Pi_{2 h}}{\partial q_{2 h}}=0$ : 


$$
\left\{\begin{array}{l}
\delta_{m}-2 k_{2} q_{2 n}^{*}-k_{2} q_{2 l}^{*}-k_{2} q_{2 h}^{*}-c_{n}-c_{\text {nature }}=0 \\
\lambda_{1}\left(\delta_{m}-k_{2} q_{2 n}^{*}-2 k_{2} q_{2 l}^{*}-k_{2} q_{2 h}^{*}\right)-c_{l}-s_{2 l}=0 \\
\lambda_{h}\left(\delta_{m}-k_{2} q_{2 n}^{*}-k_{2} q_{2 l}^{*}-2 k_{2} q_{2 h}^{*}\right)-c_{h}-s_{2 h}=0
\end{array}\right.
$$

Proof of the existence of a unique Nash equilibrium can be found in Appendix A. Combining Equation (11) and (14), the optimal values are shown as:

$$
\begin{gathered}
\left.s_{2 l}^{*}=\frac{\left(2 c_{l}-J_{21} \lambda_{l}+J_{22}\left(\begin{array}{l}
\left(3+\alpha\left(\beta+c_{h} \beta+\beta J_{21} \lambda_{h}-3\right)\right) \lambda_{l} \\
+4 k_{2} J_{23} q_{E V 1}-3 c_{l} \alpha \beta \lambda_{h}
\end{array}\right)\right)}{3 J_{22} J_{24}+4 J_{22} J_{23} k_{2} q_{E V 1}-2}\right) \\
s_{2 h}^{*}=\frac{\left(2 c_{h}-J_{21} \lambda_{h}+J_{22}\left(\begin{array}{l}
(\alpha-1)\left(3 c_{h}-J_{21} \lambda_{h}\right) \lambda_{l} \\
+\left(\left(1+c_{l}\right)(1-\alpha)+3 \alpha \beta\right) \lambda_{h}+4 k_{2} J_{23} q_{E V 1}
\end{array}\right)\right)}{3 J_{22} J_{24}+4 J_{22} J_{23} k_{2} q_{E V 1}-2}
\end{gathered}
$$

Where $\quad J_{21}=\left(c_{n}+c_{\text {nature }}+\delta_{m}\right) \quad, \quad J_{22}=A k_{2} \theta q_{E V 1} \quad, \quad J_{23}=A(\alpha-1) \alpha \beta \theta \lambda_{h} \lambda_{l} \quad$,

$$
\begin{aligned}
J_{24}=\left(\alpha \beta \lambda_{h}+\lambda_{l}-\alpha \lambda_{l}\right) . & \\
q_{2 n}^{*} & =\frac{\lambda_{h} s_{2 l}^{*}+\lambda_{l} s_{2 h}^{*}+\lambda_{l} c_{h}+\lambda_{h} c_{l}+\lambda_{l} \lambda_{h}\left(\delta_{m}-3 c_{n}-3 c_{\text {nature }}\right)}{4 k_{2} \lambda_{h} \lambda_{l}} \\
q_{2 l}^{*} & =\frac{-3 \lambda_{h} s_{2 l}^{*}+\lambda_{l} s_{2 h}^{*}+\lambda_{l} c_{h}-3 \lambda_{h} c_{l}+\lambda_{l} \lambda_{h}\left(\delta_{m}+c_{n}+c_{\text {nature }}\right)}{4 k_{2} \lambda_{h} \lambda_{l}} \\
q_{2 h}^{*} & =\frac{\lambda_{h} s_{2 l}^{*}-3 \lambda_{l} s_{2 h}^{*}+\lambda_{h} c_{l}-3 \lambda_{l} c_{h}+\lambda_{l} \lambda_{h}\left(\delta_{m}+c_{n}+c_{\text {nature }}\right)}{4 k_{2} \lambda_{h} \lambda_{l}}
\end{aligned}
$$

From Equations (15) and (16), we can see that the decision on optimal purchasing prices mainly depends on remanufacturing cost, but also is influenced by other factors such as EV market size, return yield and salvageable rate.

In Equations (17)-(19), only $s_{2 h}^{*}$ and $s_{2 l}^{*}$ are the decision variables; the rest are input constants. Therefore, we focus on how these two decision variables affect $q^{*}$. Observing the above equations, knowing that $\lambda_{h}>\lambda_{l}$, it suggests that the decision on the optimal purchasing price for low-quality returns is more influenced by $s_{2 l}^{*}$ than $s_{2 h}^{*}$. But this fact is less prominent in deciding the optimal $q_{2 h}^{*}$. In general, Equations (17)-(19) suggest the following:

- The higher the purchase price of returns, the less motivation for remanufacturing because of reduced profit. Hence, using raw materials becomes a favourable choice, as shown in Equation (17).

- The lower the purchase price of low-quality returns, $s_{2 l}^{*}$, the higher the remanufacturing of low-quality returns, $q_{2 l}^{*}$, as shown in Equation (18), which leads to the following point.

- The need for remanufacturing of high-quality returns is reducing, because the total $q_{2 l}^{*}+q_{2 h}^{*}+q_{2 n}^{*}$ is meant to cover the total demand for battery. Hence, the higher $q_{2 l}^{*}$, the lower $q_{2 n}^{*}$ and $q_{2 h}^{*}$. 
We then use $q_{2 l}^{*}+q_{2 h}^{*}$ to present the total optimal remanufacturing amount, and $q_{2 l}^{*}+q_{2 h}^{*}+q_{2 n}^{*}$ to mean the total optimal amount of manufacturing and remanufacturing. The purpose is to understand the influence of the purchase price on the (re-)manufacturing operations as a whole. From Equation (17)-(19), we have

$$
\begin{gathered}
q_{2 l}^{*}+q_{2 h}^{*}=\frac{-\lambda_{h} s_{2 l}^{*}-\lambda_{l} s_{2 h}^{*}-\lambda_{l} c_{h}-\lambda_{h} c_{l}+\lambda_{l} \lambda_{h}\left(\delta_{m}+c_{n}+c_{\text {nature }}\right)}{2 k_{2} \lambda_{h} \lambda_{l}} \\
q_{2}^{*}=q_{2 l}^{*}+q_{2 h}^{*}+q_{2 n}^{*}=\frac{-\lambda_{h} s_{2 l}^{*}-\lambda_{l} s_{2 h}^{*}-\lambda_{l} c_{h}-\lambda_{h} c_{l}+\lambda_{l} \lambda_{h}\left(3 \delta_{m}-c_{n}-c_{\text {nature }}\right)}{4 k_{2} \lambda_{h} \lambda_{l}}
\end{gathered}
$$

Observing Equations (20) and (21), we find that both $S_{2 h}^{*}$ and $S_{2 l}^{*}$ have a negative relationship between both $q_{2 l}^{*}+q_{2 h}^{*}$ and $q_{2 l}^{*}+q_{2 h}^{*}+q_{2 n}^{*}$.

- Equation (20) suggests that the higher the return purchase price, the lower the remanufacturing quantity.

- Nevertheless, the total amount of manufacturing and remanufacturing in period 2 is decided by other factors other than purchase price alone. In this case, the cost of producing new batteries and the purchase price of raw materials play important roles, as shown in Equation (21).

In summary, if we use $+/$ - to represent a positive/negative correlation relationship, the relationship between quantity and the returned battery purchase prices is shown in Table 2 below:

Table 2: Relationship between optimal quantities and purchase price in period 2

\begin{tabular}{|c|c|c|}
\hline Input variable & $s_{2 h}^{*}$ & $s_{2 l}^{*}$ \\
\hline$q_{2 l}{ }^{*}$ & + & + \\
\hline$q_{2 h}{ }^{*}$ & - & + \\
\hline$q_{2 n}{ }^{*}$ & + & - \\
\hline$q_{2 l}{ }^{*}+q_{2 h}{ }^{*}$ & - & - \\
\hline$q_{2 l}{ }^{*}+q_{2 h}{ }^{*}+q_{2 n}{ }^{*}$ & - & \\
\hline
\end{tabular}

\subsection{Nash equilibrium in period 3}

Similarly, the EV quantity desired in period 3 is

$$
q_{E V 3}=M_{E V 3}\left(1-p_{E V 3}\right)
$$

With $q_{3}=A q_{E V 3}$ and $p_{3}=\delta_{m} p_{E V 3}$, the demand for EV batteries in this period is:

$$
q_{3}=A M_{E V 3}\left(1-p_{3} / \delta_{m}\right)
$$

And letting $k_{3}=\delta_{m} /\left(A M_{E V 3}\right)$, we can achieve the price function deriving from Equation (23): 


$$
p_{3}=\delta_{m}-k_{3} q_{3}
$$

In this period, the battery material consists of raw materials, high and low quality returns and end-of-life reused battery returns. The quantity of demand for new batteries equals the total market demand minus all $\mathrm{EV}$ batteries made from returns:

$$
q_{3 n}=q_{3}-q_{3 l}-q_{3 h}-q_{3 u}
$$

And the price:

$$
p_{3}=\delta_{m}-k_{3}\left(q_{3 n}+q_{3 l}+q_{3 h}+q_{3 u}\right)
$$

The return quantity in period 3 is new batteries manufactured in period 2 multiplied by the return rate which is $A \theta q_{E V 2}$. In this period, all returns in all three classes will be recycled with the quantities:

$$
\left\{\begin{array}{l}
q_{3 l}=A \theta q_{E V 2}(1-\alpha)\left(1-s_{3 l}\right) \\
q_{3 h}=A \theta q_{E V 2} \alpha \beta\left(1-s_{3 h}\right) \\
q_{3 u}=A \theta q_{E V 2} \alpha(1-\beta)\left(1-s_{3 u}\right)
\end{array}\right.
$$

The profits for manufacturer and remanufacturer (e.g. low-quality, high-quality and reused batteries) are:

$$
\left\{\begin{array}{l}
\Pi_{3 n}=\left(p_{3}-c_{n}-c_{\text {nature }}\right) q_{3 n}=\left(\delta_{m}-k_{3}\left(q_{3 n}+q_{3 l}+q_{3 h}+q_{3 u}\right)-c_{n}-c_{\text {nature }}\right) q_{3 n} \\
\Pi_{3 l}=\lambda_{l} q_{3 l} p_{3}-\left(c_{l}+s_{3 l}\right) q_{3 l}=\lambda_{l} q_{3 l}\left(\delta_{m}-k_{3}\left(q_{3 n}+q_{3 l}+q_{3 h}+q_{3 u}\right)\right)-\left(c_{l}+s_{3 l}\right) q_{3 l} \\
\Pi_{3 h}=\lambda_{h} q_{3 h} p_{3}-\left(c_{h}+s_{3 h}\right) q_{3 h}=\lambda_{h} q_{3 h}\left(\delta_{m}-k_{3}\left(q_{3 n}+q_{3 l}+q_{3 h}+q_{3 u}\right)\right)-\left(c_{h}+s_{3 h}\right) q_{3 h} \\
\Pi_{3 u}=\lambda_{u} q_{3 u} p_{3}-\left(c_{u}+s_{3 u}\right) q_{3 u}=\lambda_{u} q_{3 u}\left(\delta_{m}-k_{3}\left(q_{3 n}+q_{3 l}+q_{3 h}+q_{3 u}\right)\right)-\left(c_{u}+s_{3 u}\right) q_{3 u}
\end{array}\right.
$$

The profits above are all convex because of:

$$
\frac{\partial^{2} \Pi_{3 n}}{\partial q_{3 n}{ }^{2}}=-2 k_{3}<0 ; \frac{\partial^{2} \Pi_{3 l}}{\partial q_{3 l}{ }^{2}}=-2 \lambda_{l} k_{3}<0 ; \frac{\partial^{2} \Pi_{3 h}}{\partial q_{3 h}{ }^{2}}=-2 \lambda_{h} k_{3}<0 ; \frac{\partial^{2} \Pi_{3 u}}{\partial q_{3 u}{ }^{2}}=-2 \lambda_{u} k_{3}<0 ;
$$

Using first-order condition to acquire the optimal profit for each agent:

$$
\left\{\begin{array}{l}
\delta_{m}-k_{3}\left(2 q_{3 n}+q_{3 l}+q_{3 h}+q_{3 u}\right)-c_{n}-c_{\text {nature }}=0 \\
\lambda_{l} \delta_{m}-\lambda_{l} k_{3}\left(q_{3 n}+2 q_{3 l}+q_{3 h}+q_{3 u}\right)-c_{l}-s_{3 l}=0 \\
\lambda_{h} \delta_{m}-\lambda_{h} k_{3}\left(q_{3 n}+q_{3 l}+2 q_{3 h}+q_{3 u}\right)-c_{h}-s_{3 h}=0 \\
\lambda_{u} \delta_{m}-\lambda_{u} k_{3}\left(q_{3 n}+q_{3 l}+q_{3 h}+2 q_{3 u}\right)-c_{u}-s_{3 u}=0
\end{array}\right.
$$

Proof of the existence of a unique Nash equilibrium can be found in Appendix B. Combining Equations (27) and (30):

$$
\begin{gathered}
s_{3 l}^{*}=\frac{\left(2 c_{l}-J_{31} \lambda_{l}+J_{32}\left(\begin{array}{l}
-3 \alpha c_{l} J_{33}+\alpha J_{32}+\lambda_{l}\left(3+\alpha\left(J_{33}+J_{31} J_{33}-2\right)\right) \\
\cdot\left(5 k_{3} J_{34} q_{E V 2}+J_{38} J_{310} \lambda_{u}+J_{39}\right)
\end{array}\right)\right)}{J_{32}\left(3 J_{35}+\alpha J_{32} J_{36}+5 \alpha k_{3} J_{32} J_{34} q_{E V 2}\right)-2} \\
s_{3 h}^{*}=\frac{\left(2 c_{h}-J_{31} \lambda_{h}+J_{32}\left(\begin{array}{l}
3 c_{h}\left(\lambda_{l} J_{37}+\alpha \lambda_{u} J_{38}\right)+\lambda_{h} J_{311} \\
+J_{32} \alpha\left(J_{38} \lambda_{u} J_{312}-J_{313}+5 k_{3} J_{34} q_{E V 2}\right)
\end{array}\right)\right)}{J_{32}\left(3 J_{35}+\alpha J_{32} J_{36}+5 \alpha k_{3} J_{32} J_{34} q_{E V 2}\right)-2}
\end{gathered}
$$




$$
s_{3 u}^{*}=\frac{\left(2 c_{u}-J_{31} \lambda_{u}+J_{32}\left(-3 c_{u}\left(\alpha \beta \lambda_{h}-\lambda_{1} J_{37}\right)+\lambda_{u} J_{314}+J_{32} \alpha\left(5 k_{3} J_{34} q_{E V 2}+J_{45}+J_{316}\right)\right)\right)}{J_{32}\left(3 J_{35}+\alpha J_{32} J_{36}+5 \alpha k_{3} J_{32} J_{34} q_{E V 2}\right)-2}
$$

Where $J_{31}=\left(c_{n}+c_{\text {nature }}+\delta_{m}\right), \quad J_{32}=A k_{3} \theta q_{E V 2}, \quad J_{33}=\beta\left(\lambda_{h}-\lambda_{u}\right)+\lambda_{u}$,

$$
\begin{aligned}
& J_{34}=A(\alpha-1) \alpha(\beta-1) \beta \theta \lambda_{h} \lambda_{l} \lambda_{u}, \quad J_{35}=\left(\lambda_{l}+\alpha\left(J_{3}-\lambda_{l}\right)\right), \\
& J_{36}=4(\alpha-1) \beta \lambda_{h} \lambda_{l}+4(\beta-1)\left(\alpha \beta \lambda_{h}+\lambda_{l}-\alpha \lambda_{l}\right) \lambda_{u}, \quad J_{37}=(\alpha-1), \quad J_{38}=(\beta-1), \\
& J_{39}=\beta \lambda_{h} \lambda_{l}\left(\alpha\left(3+c_{u} J_{38}+\beta\right)-4\right), \\
& J_{310}=\left(\left(4+\alpha \beta\left(1+c_{h}\right)+\alpha \beta J_{31} \lambda_{h}-4 \alpha\right) \lambda_{l}-4 c_{l} \alpha \beta \lambda_{h}\right), \\
& J_{311}=\left(1-c_{l} J_{37}+2 \alpha \beta+\left(c_{n}+c_{\text {nature }}\right) \lambda_{l}-\alpha J_{1}\left(\lambda_{l}+\lambda_{u} J_{38}\right)+\delta_{m} \lambda_{l}-\alpha c_{u} J_{38}\right), \\
& J_{312}=\left(\left(4 \alpha \beta-\left(1+c_{l}\right) J_{37}\right) \lambda_{h}+J_{37}\left(4 c_{h}-J_{1} \lambda_{h}\right) \lambda_{l}\right), \quad J_{313}=J_{37} \lambda_{h} \lambda_{l}\left(c_{u} J_{38}-3 \beta-1\right), \\
& J_{314}=\left(1-c_{l} J_{37}-\lambda_{l} J_{31} J_{37}+\alpha\left(2+\beta\left(c_{h}+J_{31} \lambda_{h}-2\right)\right)\right), \\
& J_{315}=\beta \lambda_{h}\left(\lambda_{u}\left(c_{l} J_{37}-3 \alpha+4 \alpha \beta-1\right)-4 \lambda_{l} c_{u} J_{37}\right), \\
& J_{316}=\lambda_{u} \lambda_{l} J_{37}\left(4+\beta\left(c_{h}+J_{31} \lambda_{h}-3\right)\right) .
\end{aligned}
$$$$
q_{3 n}^{*}=\frac{\left(\begin{array}{l}
\lambda_{u} \lambda_{h} s_{3 l}^{*}+\lambda_{u} \lambda_{l} s_{3 h}^{*}+\lambda_{h} \lambda_{l} s_{3 u}^{*} \\
+\lambda_{h} \lambda_{l} c_{u}+\lambda_{u} \lambda_{h} c_{l}+\lambda_{u} \lambda_{l} c_{h}+\lambda_{u} \lambda_{l} \lambda_{h}\left(\delta_{m}-4 c_{n}-4 c_{\text {nature }}\right)
\end{array}\right)}{5 k_{3} \lambda_{h} \lambda_{l} \lambda_{u}}
$$$$
q_{3 l}^{*}=\frac{\left(\begin{array}{l}
-4 \lambda_{u} \lambda_{h} s_{3 l}^{*}+\lambda_{u} \lambda_{1} s_{3 h}^{*}+\lambda_{h} \lambda_{l} s_{3 u}^{*} \\
+\lambda_{h} \lambda_{l} c_{u}-4 \lambda_{u} \lambda_{h} c_{l}+\lambda_{u} \lambda_{l} c_{h}+\lambda_{u} \lambda_{l} \lambda_{h}\left(c_{n}+c_{\text {nature }}+\delta_{m}\right)
\end{array}\right)}{5 k_{3} \lambda_{h} \lambda_{l} \lambda_{u}}
$$$$
q_{3 h}^{*}=\frac{\left(\begin{array}{l}
\lambda_{u} \lambda_{h} s_{3 l}^{*}-4 \lambda_{u} \lambda_{l} s_{3 h}^{*}+\lambda_{h} \lambda_{l} s_{3 u}^{*} \\
+\lambda_{h} \lambda_{l} c_{u}-4 \lambda_{u} \lambda_{l} c_{h}+\lambda_{u} \lambda_{h} c_{l}+\lambda_{u} \lambda_{h} \lambda_{l}\left(c_{n}+c_{\text {nature }}+\delta_{m}\right)
\end{array}\right)}{5 k_{3} \lambda_{h} \lambda_{l} \lambda_{u}}
$$$$
q_{3 u}^{*}=\frac{\left(\begin{array}{l}
\lambda_{u} \lambda_{l} s_{3 h}^{*}+\lambda_{u} \lambda_{h} s_{3 l}^{*}-4 \lambda_{h} \lambda_{l} s_{3 u}^{*} \\
-4 \lambda_{h} \lambda_{l} c_{u}+\lambda_{u} \lambda_{h} c_{l}+\lambda_{u} \lambda_{l} c_{h}+\lambda_{u} \lambda_{l} \lambda_{h}\left(c_{n}+c_{\text {nature }}+\delta_{m}\right)
\end{array}\right)}{5 k_{3} \lambda_{h} \lambda_{l} \lambda_{u}}
$$

In Equations (31)-(33), the decision on optimizing return purchase prices (e.g. lowquality, high-quality and reused batteries) is rather complicated. It is influenced by various factors, but certainly remanufacturing costs play a crucial role.

Equations (34)-(37) appear to have the same pattern. In general, the higher the purchase 
price for that class, the lower the remanufacturing quantity for that specific class. This makes perfect sense. Because remanufacturer's decision on the production quantity must be based on the maximizing profit. With relatively fixed remanufacturing cost, the higher purchasing price, the less profit.

In more detail, from Equations (34)-(37), with a focus on how $s_{3 h}^{*}, s_{3 l}^{*}$, $s_{3 u}^{*}$ influence the decision variables, we assume that $\lambda_{h}>\lambda_{u}>\lambda_{l} ; 4 \lambda_{u} \lambda_{h}>\lambda_{u} \lambda_{h}>\lambda_{h} \lambda_{l}>\lambda_{u} \lambda_{l}$; $4 \lambda_{h} \lambda_{l}>\lambda_{u} \lambda_{h}>\lambda_{u} \lambda_{l} ; 4 \lambda_{u} \lambda_{l}>\lambda_{u} \lambda_{h}>\lambda_{h} \lambda_{l}$. This suggests:

- $s_{3 l}^{*}$ has more influence than $s_{3 h}^{*}$ and $s_{3 u}^{*}$ on $q_{3 n}^{*}$, and it also has more impact on $q_{3 l}^{*}$.

- $s_{3 h}^{*}$ has more influence on $q_{3 h}^{*}$ and $s_{3 u}^{*}$ has more influence on $q_{3 u}^{*}$; With the addition of Equations (34)-(37), we have the following:

$$
\begin{gathered}
q_{3 l}^{*}+q_{3 h}^{*}+q_{3 u}^{*}=\frac{\left(\begin{array}{l}
-2 \lambda_{u} \lambda_{h} s_{3 l}^{*}-2 \lambda_{u} \lambda_{l} s_{3 h}^{*}-2 \lambda_{h} \lambda_{l} s_{3 u}^{*} \\
-2 \lambda_{h} \lambda_{l} c_{u}-2 \lambda_{u} \lambda_{h} c_{l}-2 \lambda_{u} \lambda_{l} c_{h}+3 \lambda_{u} \lambda_{l} \lambda_{h}\left(c_{n}+c_{\text {nature }}+\delta_{m}\right)
\end{array}\right)}{5 k_{3} \lambda_{h} \lambda_{l} \lambda_{u}} \\
q_{3}^{*}=q_{3 l}^{*}+q_{3 h}^{*}+q_{3 u}^{*}+q_{3 n}^{*}=\frac{\left(\begin{array}{l}
-\lambda_{u} \lambda_{h} s_{3 l}^{*}-\lambda_{u} \lambda_{l} s_{3 h}^{*}-\lambda_{h} \lambda_{l} s_{3 u}^{*} \\
-\lambda_{h} \lambda_{l} c_{u}-\lambda_{u} \lambda_{h} c_{l}-\lambda_{u} \lambda_{l} c_{h}+\lambda_{u} \lambda_{l} \lambda_{h}\left(-c_{n}-c_{\text {nature }}+4 \delta_{m}\right)
\end{array}\right)}{5 k_{3} \lambda_{h} \lambda_{l} \lambda_{u}}
\end{gathered}
$$

Equation (38) presents the total optimal remanufacturing amount, and Equation (39) the total optimal amount of manufacturing and remanufacturing in period 3. Comparing with period 2 , there is one more decision variable which is $s_{u}^{*}$. The result suggests the following:

- The higher return purchasing price $\left(s_{3 l}^{*}, s_{3 h}^{*}, s_{3 u}^{*}\right)$, the lower remanufacturing quantity, as shown in (38);

- $\quad$ Because of $\lambda_{u} \lambda_{h}>\lambda_{h} \lambda_{l}>\lambda_{u} \lambda_{l}, s_{3 l}^{*}$ plays more important roles in both total optimal amount of remanufacturing and total optimal amount of manufacturing and remanufacturing, compared with $s_{3 h}^{*}$ and $s_{3 u}^{*}$. Moreover, $s_{3 h}^{*}$ impacts less on those two optimal amounts while the impact of $s_{3 u}^{*}$ is between them.

To summarise, the relationship between quantity and returned battery purchase price in period 3 is shown Table 3:

Table 3: Relationship between optimal quantities and purchase price in period 3

\begin{tabular}{|c|c|c|c|}
\hline Input variable & $s_{3 h}^{*}$ & $s_{3 l}^{*}$ & $s_{3 u}^{*}$ \\
\hline$q_{3 l}{ }^{*}$ & + & - & + \\
\hline$q_{3 h}{ }^{*}$ & - & + & + \\
\hline$q_{3 u}{ }^{*}$ & + & + & - \\
\hline
\end{tabular}




\begin{tabular}{|c|c|c|c|}
\hline$q_{3 n}{ }^{*}$ & + & + & + \\
\hline${q_{3 l}}^{*}+{q_{3 h}}^{*}+q_{3 u}^{*}$ & - & - & - \\
\hline 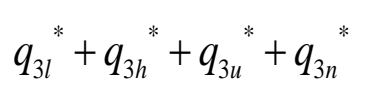 & - & - & - \\
\hline
\end{tabular}

\section{Numerical study}

\subsection{Numerical example}

In this section, we come up with a numerical example to demonstrate the model.

According to International Energy Agency (2017), EV market size is predicted to $18,000,000$ in 2020, i.e. $M_{E V}=18,000,000$. And EV battery price accounts for around $30 \%$ of electric car price i.e. $\delta_{m}=0.3$.

According to Lambert (2017) and Mark (2014), taking Tesla Model as example, the nature resources for each battery on EV costs $£ 8200$ with manufacturing cost $£ 3500$. According to Binks (2016) and Will Date (2015), it averagely costs $£ 860$ to process a used battery. We assume the low-quality used battery recycling processing cost is $£ 950$, high-quality is $£ 850$ and reusable battery is $£ 800$. To normalize the cost into the same scale, without losing generality, we set $c_{\text {nature }}=0.1$ as benchmarking, other costs other costs against the benchmark $c_{l}=0.1 * 950 / 8200=0.012$,

$c_{h}=0.1 * 850 / 8200=0.011, c_{u}=0.1 * 800 / 8200=0.01$, $c_{n}=0.1 * 3550 / 8200=0.043$.

The parameters are shown in Table 4 below:

Table 4: Numerical example parameters

\begin{tabular}{|l|l|l|l|l|}
\hline$M_{E V}=18,000,000$ & $A=4$ & $\delta_{m}=0.3$ & $\theta=0.8$ & $\alpha=0.6$ \\
\hline$\beta=0.7$ & $\lambda_{l}=0.5$ & $\lambda_{h}=0.8$ & $\lambda_{u}=0.65$ & $c_{\text {nature }}=0.1$ \\
\hline$c_{n}=0.043$ & $c_{l}=0.012$ & $c_{h}=0.011$ & $c_{u}=0.01$ & \\
\hline
\end{tabular}

In Period 1, applying Equations (1)-(5), the optimal quantity for battery raw materials (which is also the optimal total quantity) is $q_{1}^{*}=q_{1 n}^{*}=1.8 \times 10^{7}$. The optimal sale price is $p_{1}^{*}=0.221$. The optimal profit that the battery manufacturer will achieve is $\Pi_{1 n}^{*}=1.49 \times 10^{6}$.

In period 2, we substitute $q_{E V 1}^{*}=4.72 \times 10^{6}$ as the initial parameter by applying Equation (1). Through applying Equation (15)-(19), the optimal values are shown below:

Table 5: Optimal values in period 2

\begin{tabular}{|c|c|c|c|c|}
\hline$s_{2 l}^{*}=0.076$ & $s_{2 h}^{*}=0.13$ & $q_{2 l}^{*}=5.58 \times 10^{6}$ & $q_{2 h}^{*}=5.51 \times 10^{6}$ & $q_{2 n}^{*}=1.33 \times 10^{7}$ \\
\hline \multicolumn{3}{|c|}{ Total quantity of battery material } & \multicolumn{2}{|l|}{$q_{2}^{*}=2.22 \times 10^{7}$} \\
\hline \multicolumn{3}{|c|}{ Optimal sale price for EV battery } & \multicolumn{2}{|l|}{$p_{2}^{*}=16236$} \\
\hline \multicolumn{3}{|c|}{ Profit for low-quality EV battery remanufacturer } & \multicolumn{2}{|l|}{$\Pi_{2 l}^{*}=64926$} \\
\hline \multicolumn{3}{|c|}{ Profit for high-quality EV battery remanufacturer } & \multicolumn{2}{|l|}{$\Pi_{2 h}^{*}=101560$} \\
\hline \multicolumn{3}{|c|}{ Profit for new EV battery manufacturer } & \multicolumn{2}{|l|}{$\Pi_{2 n}^{*}=740030$} \\
\hline
\end{tabular}


In period 3, through Equation (6), we substitute $q_{E V 2}^{*}=6.11 \times 10^{6}$ as the initial EV quantity in this period. The optimal values are derived by using Equations (31)-(37), as in Table 6:

Table 6: Optimal values in period 3

\begin{tabular}{|l|l|l|l|}
\hline$s_{3 l}^{*}=0.065$ & $s_{3 h}^{*}=0.113$ & $s_{3 u}^{*}=0.102$ & \\
\hline$q_{3 l}^{*}=7.31 \times 10^{6}$ & $q_{3 h}^{*}=7.28 \times 10^{6}$ & $q_{3 u}^{*}=4.72 \times 10^{6}$ & $q_{3 n}^{*}=1.00 \times 10^{7}$ \\
\hline Entire quantity for the battery material & $q_{3}^{*}=2.93 \times 10^{7}$ \\
\hline Optimal sale price for EV battery & $p_{3}^{*}=14596$ \\
\hline Profit for low quality EV battery remanufacturer & $\Pi_{3 l}^{*}=87427$ \\
\hline Profit for high quality EV battery remanufacturer & $\Pi_{3 h}^{*}=138820$ \\
\hline Profit for re-used EV battery remanufacturer & $\Pi_{3 u}^{*}=20443$ \\
\hline Profit for new EV battery manufacturer & $\Pi_{3 n}^{*}=351840$ \\
\hline
\end{tabular}

\subsection{Analysis}

In this section, we study the relationship between the parameters (i.e. $\theta, \alpha, \beta, \lambda_{l}, \lambda_{h}$, $\lambda_{u}$ ) and (re)manufacturer's profit in each period. The first column in Figures 2-7 shows profit in period 2; the second column shows profit in period 3; and the third column compares the total profit in periods 2 and 3.

In order to better study the parameters' features, we keep the market size among three periods fixed. The initial input variables are given in Table 7:

Table 7: Value of parameters

\begin{tabular}{|l|l|l|l|l|}
\hline$M_{E V}=18,000,000$ & $A=4$ & $\delta_{m}=0.3$ & $\theta=0.8$ & $\alpha=0.6$ \\
\hline$\beta=0.7$ & $\lambda_{l}=0.5$ & $\lambda_{h}=0.8$ & $\lambda_{u}=0.65$ & $c_{\text {nature }}=0.1$ \\
\hline$c_{n}=0.043$ & $c_{l}=0.012$ & $c_{h}=0.011$ & $c_{u}=0.01$ & \\
\hline
\end{tabular}

1) Analysis of return rate and sorting proportion $(\theta, \alpha, \beta)$

We set $\theta \in[0.10 .9]$ while fixing other parameters as shown in Table 7 .
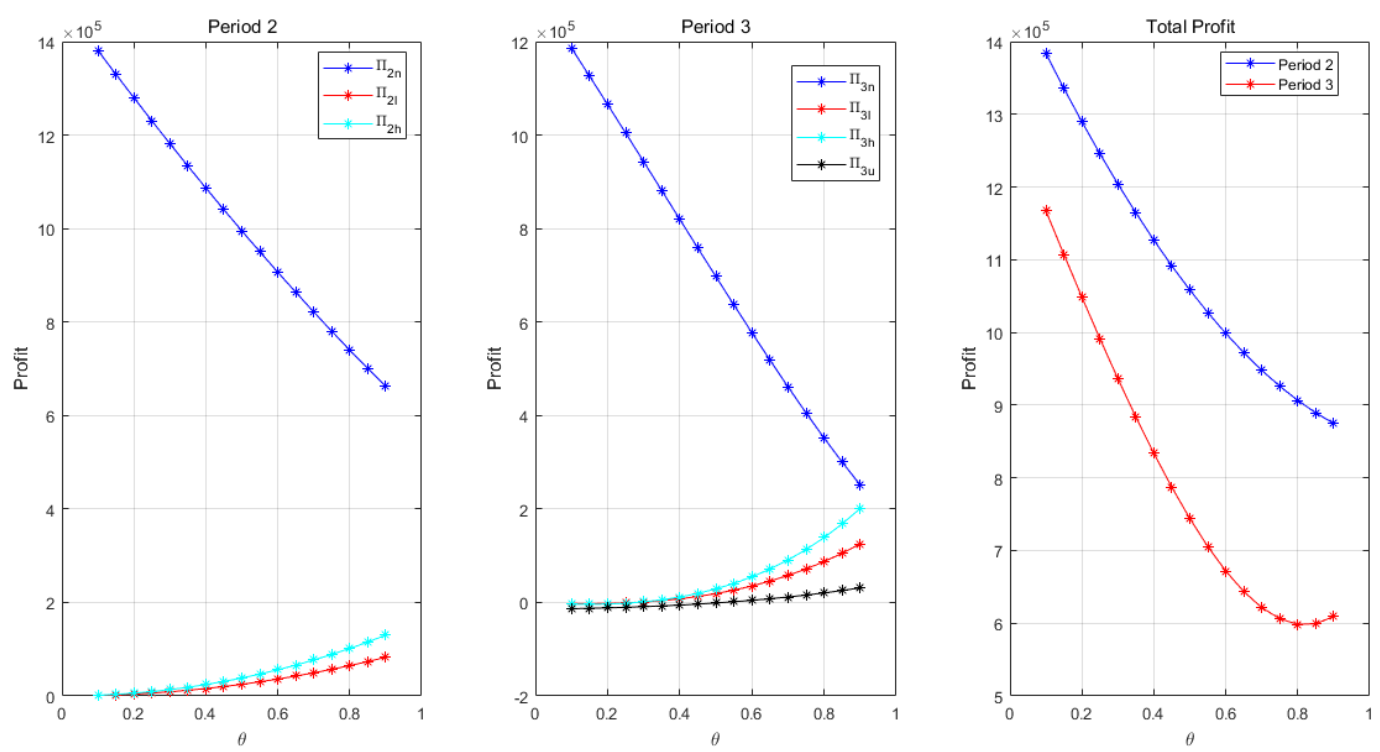

Figure 2: $\theta$ vs Profit in Period 2 and Period 3 
With the return rate $\theta$ increasing, the profit for the manufacturer is decreasing while the profit for the remanufacturer is increasing. The profit for manufacturer is always greater than that for the remanufacturer. It can be found that the profit on high quality returns is greater than that for low-quality returns. The profit achieved from reused battery recycling is the lowest. Furthermore, through comparing the varying trend of profits between periods 2 and 3 in Figure 2, for $\theta$, the profits for manufacturer, low quality return remanufacturer, high quality return remanufacturer are more sensitive in period 3. Furthermore, the higher $\theta$, the less total profit in period 2 and 3 . But the total profit for period 3 is increasing when $\theta>0.8$.

Now we discuss the high-quality return rate $\alpha$. The results are shown in Figure 3. In general, with increasing $\alpha$, (which also means a higher low-quality return rate), the profit for high quality remanufacturing increases, which is opposite trend to low quality remanufacturer. In period 3, both manufacturer and 'reused' remanufacturer's profits are insensitive to $\alpha$ although slight increase can be observed. However, low quality remanufacturer's profit is getting less and less, with $\alpha=0.9$, its profit $\left(\Pi_{l}^{*}\right)$ is even close to 0 . On the contrary, the profit for high quality remanufacturer, $\Pi_{h}^{*}$, is increasing. Because low quality remanufacturer cannot make profit if they don't have returned batteries when $\alpha$ close to 1 , while in this case, high quality remanufacturer will have more returns to make profit. Base on this, total profit is decreased when $\alpha$ is low but it increases when $\alpha$ is high.
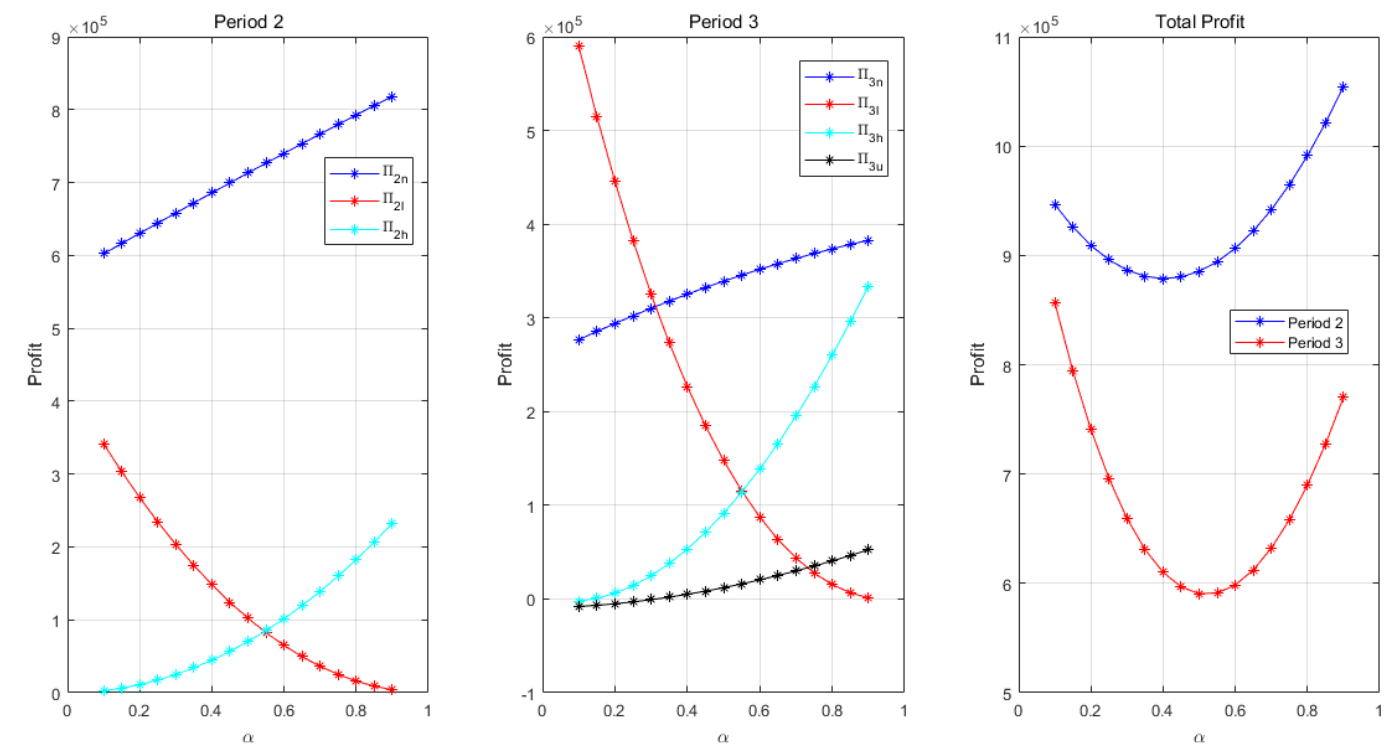

Figure 3: $\alpha$ vs Profit in Period 2 and Period 3

The reusable battery return rate, $(1-\beta)$, has limited impact on low quality return's remanufacturer $\left(\Pi_{l}^{*}\right)$. In period 3 , the more the reusable battery, the higher the profit for manufacturer $\left(\Pi_{n}^{*}\right)$ and for the reusable battery remanufacturer $\left(\Pi_{u}^{*}\right)$ as well, but less profit for high-quality returned battery remanufacturer $\left(\Pi_{h}^{*}\right)$. Furthermore, higher reusable battery return will lead to high total profit in period 2. But in period 3, with increasing of $(1-\beta)$, the total profit in period 3 shows a tendency to decrease first and then increase afterwards. 

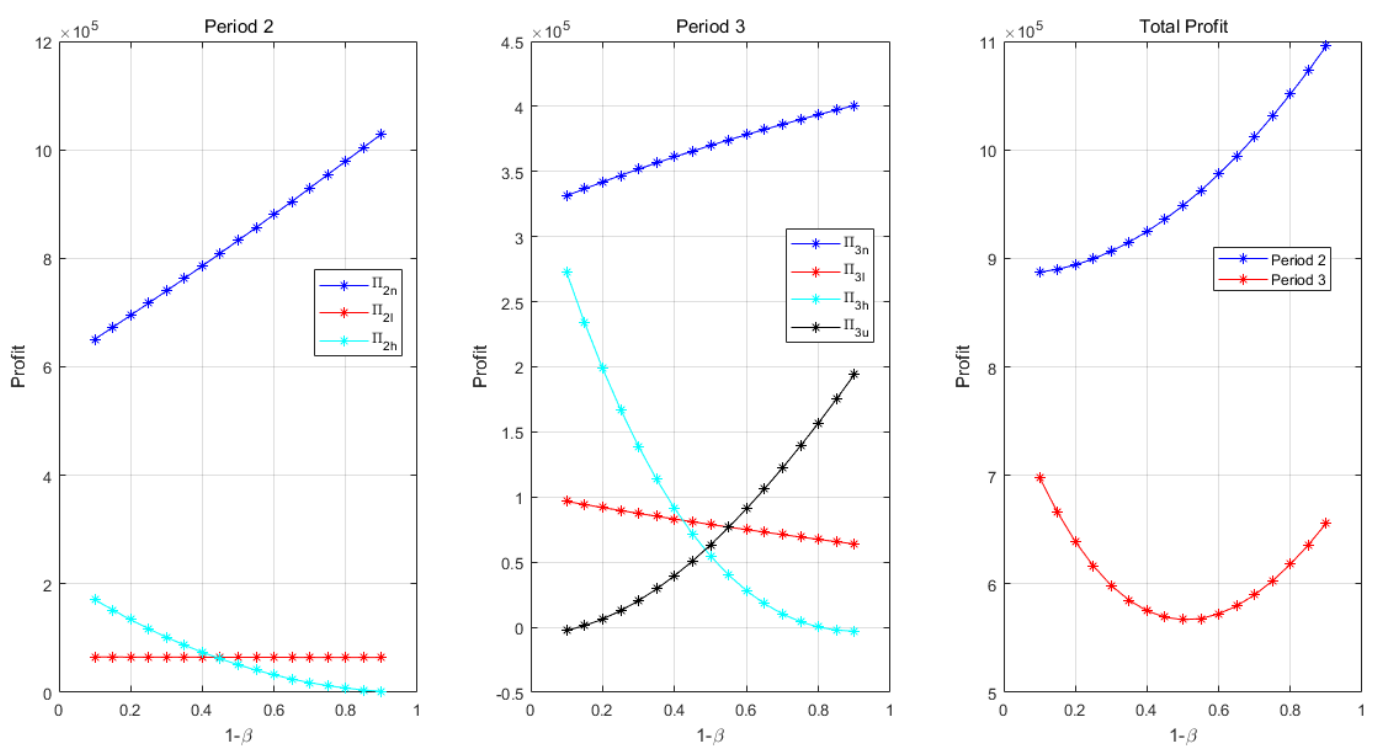

Figure 4: $1-\beta$ vs Profit in Period 2 and Period 3

2) Analysis of remanufacturing rate $\left(\lambda_{l}, \lambda_{h}, \lambda_{u}\right)$

As can be seen in Figure 5, with the increasing of low quality returned battery remanufacturing rate $\lambda_{l}, \Pi_{2 h}^{*}$ and $\Pi_{3 u}^{*}$ is constant. Meanwhile, $\Pi_{2 n}^{*}, \Pi_{2 l}^{*}, \Pi_{3 n}^{*}$ and $\Pi_{3 l}^{*}$ are increasing slowly. The total profit in both period 2 and period 3 are keep increasing.
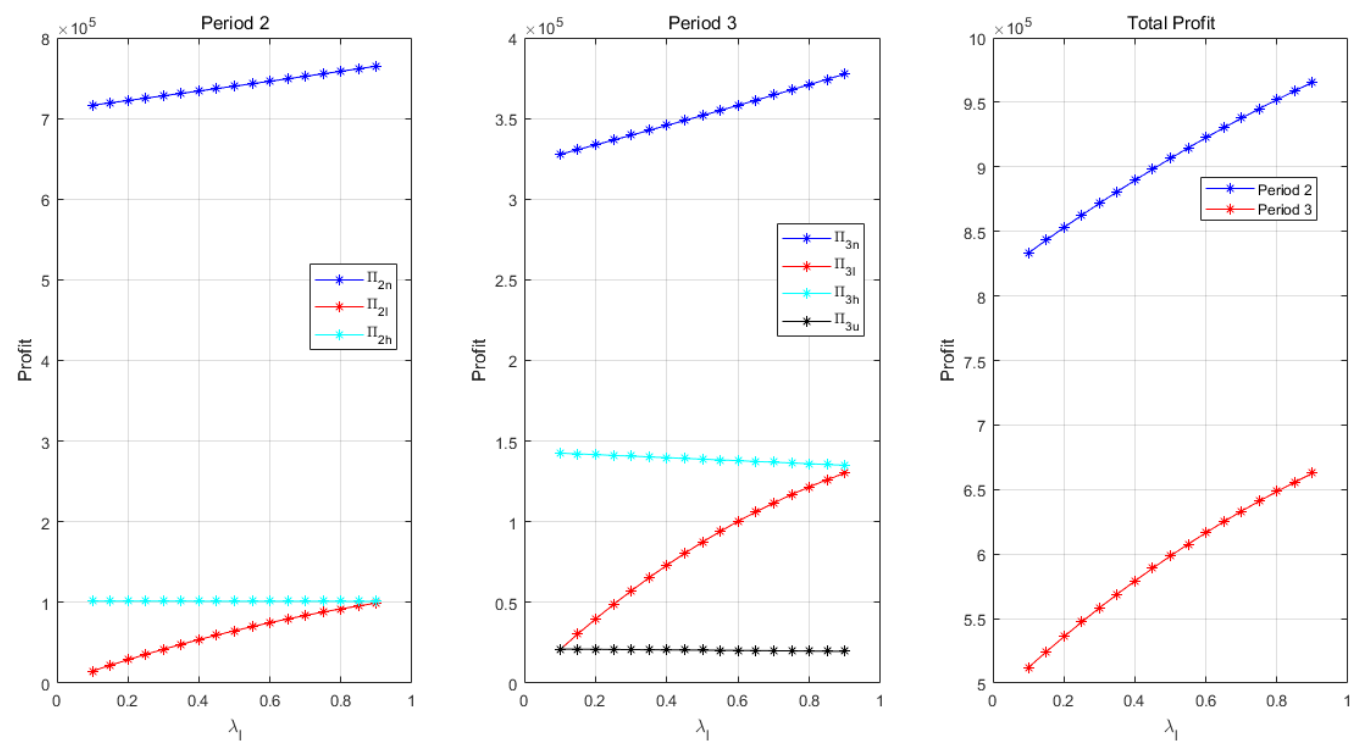

Figure 5: $\lambda_{1}$ vs Profit in Period 2 and Period 3

Considering $\lambda_{h}$, high quality returned battery remanufacturing rate, as shown in Figure 6, when it increases, profits are increasing except $\Pi_{2 l}^{*}\left(\Pi_{2 l}^{*}\right.$ keeps constant as there is no relationship between them). However, in period 3, all profits are decreased (but a tiny increase in low $\lambda_{h}$ ). This results from the increasing returned batteries' purchase price. Combining these two, the total profit in period 2 is rising while the profit in period 3 is increasing first and keep dropping down when $\lambda_{h}>0.4$. 

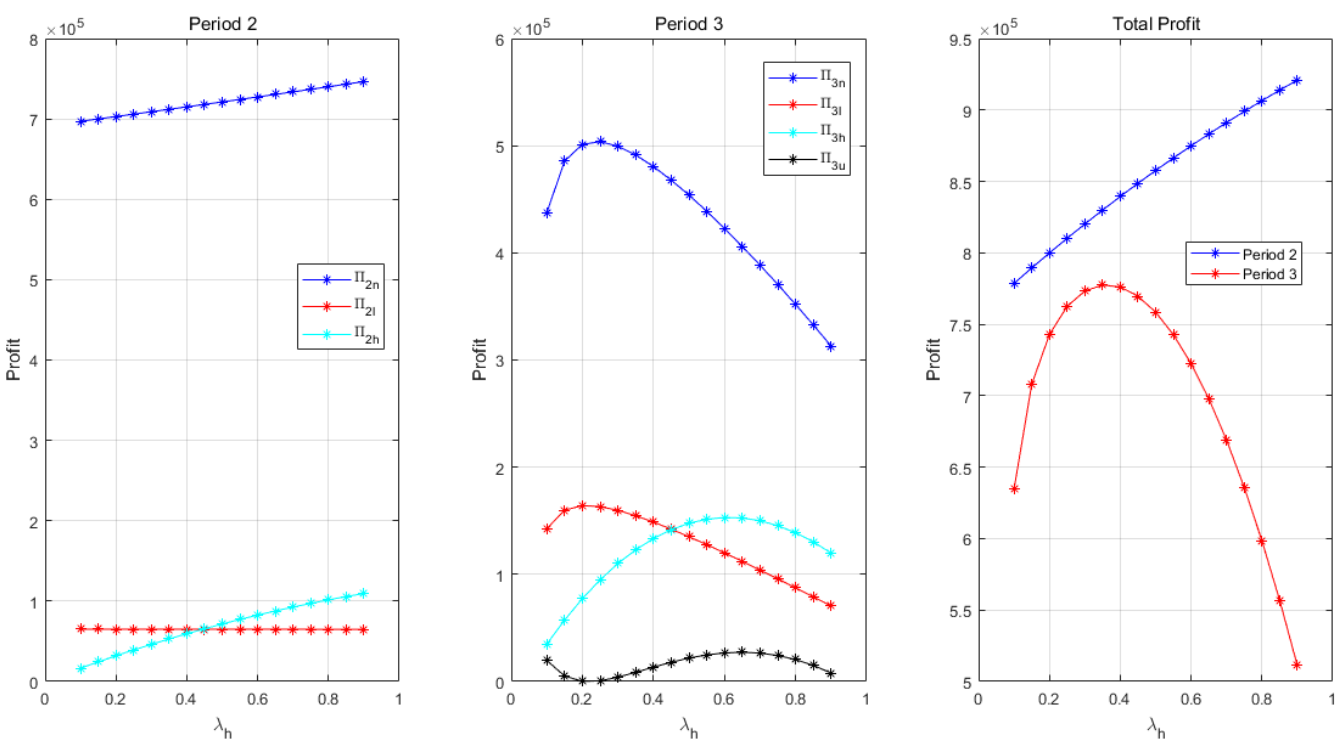

Figure 6: $\lambda_{h}$ vs Profit in Period 2 and Period 3

The reused battery remanufacturing rate $\lambda_{u}$ only works in period 3 . As we can find in Figure 7 , with the condition of low $\lambda_{u}$, profits for manufacturer and remanufacturer are even negative. Meanwhile, the higher the remanufacturing rate for reused batteries, the higher the profit to both manufacturer and remanufacturer.
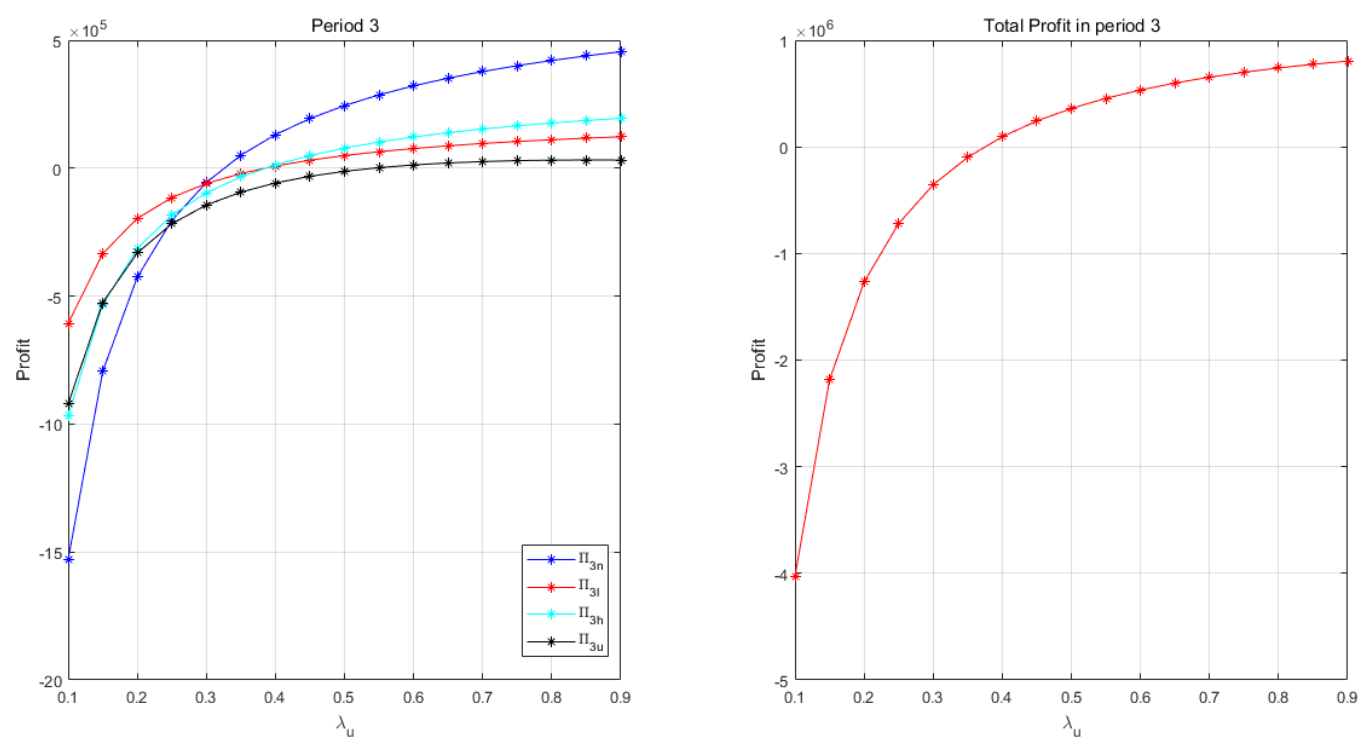

Figure 7: $\lambda_{u}$ vs Profit in Period 3

In summary, different parameters have different sensitivities and variation tendencies for each (re)manufacturer's profit in different periods.

- The manufacturer normally gets more profit than the remanufacturer (except the case about low high-quality return rate in period 3).

- $\quad$ All parameters are more sensitive in period 3 than period 2.

- With the increase of $\theta$, the remanufacturer's profit increases.

- Increasing $\alpha$ will result in more profit for the manufacturer, high-quality remanufacturer and re-usable remanufacturer, but less profit for the low- 
quality returns remanufacturer.

- Recycling rates $\left(\lambda_{1}, \lambda_{h}, \lambda_{u}\right)$ have less sensitivity than the sorting rate $(\theta, \alpha$, $(1-\beta))$. Except for $\lambda_{h}$ in period 3, profits for each participant in this model show a small increase or remain the same.

One of the most significant findings, from observing the above figures is that the total profit in period 3 is always smaller than that in period 2. The reason is that, because of the increase in returned batteries over these periods, the profit for the battery manufacturer (which occupies the majority of total profit) is decreasing and this has a direct impact on total profit.

Therefore, to maintain the profit balance between manufacturer and remanufacturer, and to promote battery recycling, the government should pay close attention to policy and incentive mechanisms to enhance the total battery return rate $(\theta)$ and the highquality return rate $(\beta)$. Some technologies also need to be developed to improve recycling efficiency, which will improve the total profit for the whole supply chain.

\section{Conclusion}

In this paper, we develop a three-period EV battery recycling and reuse model. We determine the unique Nash equilibrium among new EV battery manufacturer, low quality battery remanufacturer and high-quality battery remanufacturer as well as re-used battery remanufacturer. The purpose is to maximize individual's profit through optimal purchase price and production quantity.

We also analyze the influencing factors for the optimal (re)manufacturing quantity. The result of the analyses suggests that: (a) among the variables that have an impact on the (re-)manufacturing decision, the purchase price of returned batteries plays a critical role. Particularly, the price of low-quality returns has more influence than that of highquality returns. (b) Interestingly, a higher purchasing price for re-usable returns does not necessarily lead to higher return rate of reusable returns. (c) The manufacturer's profit is always higher than remanufacturer's. This suggests the need to design incentives to promote the remanufacturing sector. (d) Although it is appreciated that maximising the utilisation of a battery over its life-cycle would benefit the environment, the economic benefit needs further investigation.

Implication of the research results to practitioners have threefold: (1) Special attention needs to be paid on low-quality returns as it has more significant impact on total profit; (2) Although high-quality return is encouraged, monetary incentive to obtain high-quality returns may not necessarily work; (3) To sustain recycling business, government support is vitally important to keep the business going.

This paper develops the model based on the reality that most manufacturers and remanufacturers make decisions based on their own interests, the profit. There is a lack of coordination among the participants to achieve the maximized total profit for the EV battery CLSC. This leads to our suggestion for future research. In addition, our model suggests that reusing returned batteries does not bring economic benefits. How to realize the benefits for the environment and the economy at same time needs further investigation.

\section{Reference}

Ahmadi, L., Yip, A., Fowler, M., Young, S.B. and Fraser, R.A. (2014),

"Environmental feasibility of re-use of electric vehicle batteries", Sustainable 
Energy Technologies and Assessments, Elsevier Ltd, Vol. 6, pp. 64-74.

Assuncao, A., Moura, P.S. and de Almeida, A.T. (2016), "Technical and economic assessment of the secondary use of repurposed electric vehicle batteries in the residential sector to support solar energy”, Applied Energy, Vol. 181, pp. 120131.

Atasu, A., Sarvary, M. and Van Wassenhove, L.N. (2008), "Remanufacturing as a Marketing Strategy”, Management Science, Vol. 54 No. 10, pp. 1731-1746.

Ayre, J. (2016), "Nissan Reuses EV Batteries For Home Energy Storage xStorage”, Cleantechnica, available at:

https://cleantechnica.com/2016/05/15/nissan-recycles-ev-batteries-home-energystorage/ (accessed 30 December 2016).

Aziz, M., Oda, T. and Kashiwagi, T. (2015), “Extended Utilization of Electric Vehicles and their Re-used Batteries to Support the Building Energy Management System”, Energy Procedia, Elsevier B.V., Vol. 75, pp. 1938-1943.

Berg, S. (2009), "Recycling Used Lead Acid Batteries", The Schumacher Institute for Technology and Development, Vol. 44 No. 871954.

Binks, S. (2016), "Battery Recycling Process”, available at: https://www.removemycar.co.uk/battery-recycling.html (accessed 8 August 2017).

Bulmus, S.C., Zhu, S.X. and Teunter, R. (2014), “Competition for cores in remanufacturing”, European Journal of Operational Research, Elsevier B.V., Vol. 233 No. 1, pp. 105-113.

Cai, X., Lai, M., Li, X., Li, Y. and Wu, X. (2014), “Optimal acquisition and production policy in a hybrid manufacturing/ remanufacturing system with core acquisition at different quality levels”, European Journal of Operational Research, Elsevier B.V., Vol. 233 No. 2, pp. 374-382.

Dalton, A. (2016), "BMW will repurpose i3 batteries for home energy storage”, Engadget, available at: https://www.engadget.com/2016/06/21/bmw-willrepurpose-i3-batteries-for-home-energy-storage/ (accessed 30 December 2016).

Debo, L.G., Toktay, L.B. and Van Wassenhove, L.N. (2005), “Market segmentation and product technology selection for remanufacturable products", Management Science, INFORMS, Vol. 51 No. 8, pp. 1193-1205.

Erp-batteries. (2012), "How are batteries recycled?"

Ferguson, M. and Toktay, L.B. (2006), “The Effect of Competition on Recovery Strategies”, Production and Operations Management, Vol. 15 No. 3, pp. 351368.

Ferrer, G. and Swaminathan, J.M. (2010), "Managing new and differentiated remanufactured products”, European Journal of Operational Research, Elsevier B.V., Vol. 203 No. 2, pp. 370-379.

Fred Lambert. (2017), “Tesla is now claiming 35\% battery cost reduction at 'Gigafactory 1' - hinting at breakthrough cost below \$125/kWh | Electrek”, available at: https://electrek.co/2017/02/18/tesla-battery-cost-gigafactory-model3/ (accessed 8 August 2017).

Gaines, L. and Singh, M. (1995), “Energy and Environmental Impacts of Electric 
Vehicle Battery Production and Recycling”, Argonne National Laboratory, available at:

http://www.osti.gov/bridge/product.biblio.jsp?osti_id=201715\%5Cnhttp://www. osti.gov/bridge/servlets/purl/201715-9UFfKK/webviewable/.

International Energy Agency. (2017), “Global EV Outlook 2017: Two million and counting”, IEA Publications, pp. 1-71.

International Energy Agengy. (2016), “Global EV Outlook 2016 Beyond one million electric cars”.

Kelty, K. (2011), “Tesla’s Closed Loop Battery Recycling Program”, Tesla, available at: https://www.tesla.com/blog/teslas-closed-loop-battery-recycling-program.

Lih, W.-C., Yen, J.-H., Shieh, F.-H. and Liao, Y.-M. (2012), "Second use of retired lithium-ion battery packs from electric vehicles: technological challenges, cost analysis and optimal business model”, Computer, Consumer and Control (IS3C), 2012 International Symposium on, IEEE, pp. 381-384.

Majumder, P. and Groenevelt, H. (2001), “Competition in remanufacturing”, Production and Operations Management, Vol. 10 No. 2, pp. 125-141.

Mark, M. (2014), “The backgground fot Tesla Model S Battery”, available at: https://xueqiu.com/8940100817/30082286 (accessed 8 August 2017).

McIntire-Strasburg, J. (2015), “The Electric Vehicle Battery 'Can And Should Be Recycled”, Cleantechnica, available at: https://cleantechnica.com/2015/07/23/electric-vehicle-battery-can-recycled/.

Mitra, S. and Webster, S. (2008), "Competition in remanufacturing and the effects of government subsidies”, International Journal of Production Economics, Vol. 111 No. 2, pp. 287-298.

Neubauer, J. and Pesaran, A. (2010), "PHEV/EV Li-Ion Battery Second-Use Project”, National Renewable Energy Laboratory, No. April.

Neubauer, J. and Pesaran, A. (2011), “The ability of battery second use strategies to impact plug-in electric vehicle prices and serve utility energy storage applications”, Journal of Power Sources, Elsevier B.V., Vol. 196 No. 23, pp. 10351-10358.

Nissan. (2015), “Recycling Your Old Car Battery”, Nissan, available at: https://www.nissan.co.uk/recycle-your-old-car-battery.html.

Patten, J., Christensen, N., Nola, G. and Srivastava, S. (2011), "Electric vehicle battery - Wind storage system”, 2011 IEEE Vehicle Power and Propulsion Conference, VPPC 2011, pp. 1-3.

Tesla. (2016), “Model S”, available at: https://www.tesla.com/en_GB/models (accessed 30 December 2016).

Turner, K. and Heusinger, K. Von. (1984), “Drive Electric”, Industrial Management \& Data Systems, MCB UP Ltd, Vol. 84 No. 1/2, pp. 19-21.

Voelcker, J. (2016), "Reusing electric-car batteries: great idea, lots of practical challenges”, Greencarreports, available at: http://www.greencarreports.com/news/1103363_reusing-electric-car-batteriesgreat-idea-lots-of-practical-challenges (accessed 30 December 2016).

Volkswagen. (2016), “Battery Recycling”, available at: 
http://www.volkswagen.co.uk/about-us/environment/battery-recycling.

Webster, S. and Mitra, S. (2007), "Competitive strategy in remanufacturing and the impact of take-back laws”, Journal of Operations Management, Vol. 25 No. 6, pp. 1123-1140.

Will Date. (2015), “Battery recycling costs expected to shoot up”, available at: http://www.letsrecycle.com/news/latest-news/battery-collection-costs-expectedto-shoot-up/ (accessed 8 August 2017).

Yu, H.J., Zhang, T.Z., Yuan, J., Li, C.D. and Li, J.M. (2013), “Trial study on EV battery recycling standardization development”, Advanced Materials Research, Vol. 610, Trans Tech Publ, pp. 2170-2173. 


\section{Appendix A}

Proof of exitance and uniqueness of Nash equilibrium in period 2

Combining equations (11) and (14), we have simultaneous equations

$$
\left\{\begin{array}{c}
-2 k_{2} q_{2 n}-k_{2} q_{2 l}-k_{2} q_{2 h}=c_{n}+c_{\text {nature }}-\delta_{m} \\
-\lambda_{l} k_{2} q_{2 n}-2 \lambda_{l} k_{2} q_{2 l}-\lambda_{l} k_{2} q_{2 h}-s_{2 l}=c_{l}-\lambda_{l} \delta_{m} \\
-\lambda_{h} k_{2} q_{2 n}-\lambda_{h} k_{2} q_{2 l}-2 \lambda_{h} k_{2} q_{2 h}-s_{2 h}=c_{h}-\lambda_{h} \delta_{m} \\
q_{2 h}+A \theta q_{E V 1} \alpha \beta s_{2 h}=A \theta q_{E V 1} \alpha \beta \\
q_{2 l}+A \theta q_{E V 1}(1-\alpha) s_{2 l}=A \theta q_{E V 1}(1-\alpha)
\end{array}\right.
$$

The simultaneous equations above can be rewritten as

$$
A X=B
$$

Where

$$
\begin{aligned}
& A=\left[\begin{array}{ccccc}
-2 k_{2} & -k_{2} & -k_{2} & 0 & 0 \\
-\lambda_{1} k_{2} & -2 \lambda_{1} k_{2} & -\lambda_{1} k_{2} & -1 & 0 \\
-\lambda_{h} k_{2} & -\lambda_{h} k_{2} & -2 \lambda_{h} k_{2} & 0 & -1 \\
0 & 0 & 1 & 0 & A \theta q_{E V 1} \alpha \beta \\
0 & 1 & 0 & A \theta q_{E V 1}(1-\alpha) & 0
\end{array}\right] \\
& X=\left[\begin{array}{lllll}
q_{2 n} & q_{2 l} & q_{2 h} & s_{2 l} & s_{2 h}
\end{array}\right]^{\prime} \\
& B=\left[\begin{array}{c}
c_{n}+c_{\text {nature }}-\delta_{m} \\
c_{l}-\lambda_{l} \delta_{m} \\
c_{h}-\lambda_{h} \delta_{m} \\
A \theta q_{E V 1} \alpha \beta \\
A \theta q_{E V 1}(1-\alpha)
\end{array}\right]
\end{aligned}
$$

Based on Linear algebra, it can be found that the rank for A and B has relationship

$$
r(A)=r(B)=5
$$

So, there is a solution and the only solution for simultaneous equations. Hence, period 2 has an exitance and uniqueness of Nash equilibrium.

End. 


\section{Appendix B}

Proof of exitance and uniqueness of Nash equilibrium in period 3

Combining equations (27) and (30), we have

$$
\left\{\begin{array}{c}
-2 k_{3} q_{3 n}-k_{3} q_{3 l}-k_{3} q_{3 h}-k_{3} q_{3 u}=c_{n}+c_{\text {nature }}-\delta_{m} \\
-\lambda_{l} k_{3} q_{3 n}-2 \lambda_{l} k_{3} q_{3 l}-\lambda_{l} k_{3} q_{3 h}-\lambda_{l} k_{3} q_{3 u}-s_{3 l}=c_{l}-\lambda_{l} \delta_{m} \\
-\lambda_{h} k_{3} q_{3 n}-\lambda_{h} k_{3} q_{3 l}-2 \lambda_{h} k_{3} q_{3 h}-\lambda_{h} k_{3} q_{3 u}-s_{3 h}=c_{h}-\lambda_{h} \delta_{m} \\
-\lambda_{u} k_{3} q_{3 n}-\lambda_{u} k_{3} q_{3 l}-\lambda_{u} k_{3} q_{3 h}-2 \lambda_{u} k_{3} q_{3 u}-s_{3 u}=c_{u}-\lambda_{u} \delta_{m} \\
q_{3 l}+A \theta q_{E V 2}(1-\alpha) s_{3 l}=A \theta q_{E V 2}(1-\alpha) \\
q_{3 h}+A \theta q_{E V 2} \alpha \beta s_{3 h}=A \theta q_{E V 2} \alpha \beta \\
q_{3 u}+A \theta q_{E V 2} \alpha(1-\beta) s_{3 u}=A \theta q_{E V 2} \alpha(1-\beta)
\end{array}\right.
$$

The simultaneous equations above can be rewritten as

$$
A X=B
$$

Where

$$
\begin{aligned}
& A=\left[\begin{array}{ccccccc}
-2 k_{3} & -k_{3} & -k_{3} & -k_{3} & 0 & 0 & 0 \\
-\lambda_{l} k_{3}-2 \lambda_{l} k_{3} & -\lambda_{l} k_{3} & -\lambda_{l} k_{3} & -1 & 0 & 0 \\
-\lambda_{h} k_{3}-\lambda_{h} k_{3} & -2 \lambda_{h} k_{3} & -\lambda_{h} k_{3} & 0 & -1 & 0 \\
-\lambda_{u} k_{3} & -\lambda_{u} k_{3} & -\lambda_{u} k_{3} & -2 \lambda_{u} k_{3} & 0 & 0 & -1 \\
0 & 1 & 0 & 0 & A \theta q_{E V 2}(1-\alpha) & 0 & 0 \\
0 & 0 & 1 & 0 & 0 & A \theta q_{E V 2} \alpha \beta & 0 \\
0 & 0 & 0 & 1 & 0 & 0 & A \theta q_{E V 2} \alpha(1-\beta)
\end{array}\right] \\
& X=\left[\begin{array}{lllllll}
q_{3 n} & q_{3 l} & q_{3 h} & q_{3 u} & s_{3 l} & s_{3 h} & s_{3 u}
\end{array}\right]^{\prime} \\
& B=\left[\begin{array}{c}
c_{n}+c_{\text {nature }}-\delta_{m} \\
c_{l}-\lambda_{l} \delta_{m} \\
c_{h}-\lambda_{h} \delta_{m} \\
c_{u}-\lambda_{u} \delta_{m} \\
A \theta q_{E V 2}(1-\alpha) \\
A \theta q_{E V 2} \alpha \beta \\
A \theta q_{E V 2} \alpha(1-\beta)
\end{array}\right]
\end{aligned}
$$

Based on Linear algebra, it can be found that the rank for A and B has relationship

$$
r(A)=r(B)=7
$$

So, there is a solution and the only solution for simultaneous equations. Hence, period 3 has an exitance and uniqueness of Nash equilibrium.

End. 